\title{
Poluição difusa urbana por compostos inorgânicos: avaliação da contribuição dos componentes do amianto presente nas telhas de fibrocimento e nos freios de veículos
}

\author{
Diffuse pollution by urban inorganic compounds: \\ assessment of the contribution of the components \\ present in the asbestos cement roofing tiles and brakes of \\ vehicles
}

Ellen Mayara Sottoriva Conselho de Desenvolvimento Pontifícia Universidade Católica do Paraná Imaculada Conceição, 1155, Prado Velho Curitiba - PR - Brasil CEP 80215-901 Tel.: (41) 3271-1599 E-mail: mayarasottoriva@hotmail.com

Carlos Mello Garcias Instituto de Saneamento Ambiental, Centro de Integração de Tecnologia Pontifícia Universidade Católica do Paraná Tel.: (41) 3271-1598 E-mail: carlos.garcias@pucpr.br

Recebido em 21/10/10 Aceito em 10/06/11

\section{Ellen Mayara Sottoriva Carlos Mello Garcias}

\section{Resumo}

A poluição difusa é caracterizada por impurezas de origem natural ou antrópica. Pela chuva as partículas são carreadas para os corpos hídricos. A quantificação e a caracterização dessa fonte poluidora são dificultadas pela dispersão das partículas nas águas. $\mathrm{O}$ amianto é um conjunto de minerais compostos basicamente de silicato de magnésio hidratado, está presente em diversos produtos brasileiros e é considerado altamente cancerígeno em qualquer de suas formas. O presente trabalho consistiu na avaliação da contribuição do mineral nas telhas de fibrocimento e nos freios dos veículos mais antigos na poluição difusa. O estudo foi realizado na Bacia do Rio Belém, onde foram determinados oito pontos amostrais, sendo quatro pontos para a análise do fluxo de veículos e quatro para as coberturas com telhados. Nos resultados não foi possível identificar a concentração das partículas nas águas do rio, sendo sugerido que os procedimentos utilizados não sejam os únicos, mas sim complementados com análises mais específicas.

Palavras-chave: Poluição difusa. Amianto. Telhas de fibrocimento. Rio Belém.

\begin{abstract}
Diffuse pollution is characterized by impurities from natural or anthropogenic origin. Through rain drops, particles are carried to water bodies. The quantification and characterization of this pollution source are hampered by the dispersion of particles in water. Asbestos is a group of minerals composed basically of hydrated magnesium silicate, it is found in several Brazilian products, and it is considered highly carcinogenic in any form. The aim of this study was to assess the contribution of the mineral on cement fiber tiles and in the brakes of older vehicles in the diffuse polution. The investigation was carried out in the river basin of the Belem River. Eight sampling points were chosen: four points for the analysis of traffic flow and four points to analyze roofs of buildings. In the results, could not identify theit was not possible to identify concentration of particles in the river waters, suggesting that these procedures should be supplemented by more specific analysis in future studies.

Keywords: Diffuse Pollution. Asbesto. Cement Tile. Rio Belém.
\end{abstract}




\section{Introdução}

As poluições são caracterizadas como alterações indesejáveis no meio ambiente que podem causar danos ou prejuízos aos seres humanos e ao próprio ambiente. As fontes dessa poluição podem ter características pontuais ou difusas. As fontes pontuais são consideradas localizadas; geralmente estão em locais onde as contaminações atingem o meio aquático de forma concentrada. Possuem fácil visualização, devido a existirem tubulações aparentes ou um significativo acúmulo de resíduos em uma pequena área. As fontes difusas, por se tratarem de impurezas, possuem uma dispersão maior no corpo hídrico, dificultando a quantificação e a caracterização das fontes poluidoras. As áreas que apresentam mais frequência desse tipo de poluição são caracterizadas por haver atividades em torno do rio (BILBAO, 2007; ANDREOLI et al., 2003; TOMAZ, 2006).

Os freios dos veículos e as telhas, objetos de estudo desta pesquisa, são fontes diretas da contaminação do meio com micropoluentes devido à circulação de veículos nos ambientes urbanos e do próprio intemperismo, que favorece o desgaste das telhas. Nas últimas décadas, tanto o trânsito de veículos nos ambientes urbanos tem-se tornado mais intenso como a quantidade de coberturas com telhas de cimento amianto é expressiva, devido ao baixo custo desse material.

Por meio da precipitação hídrica e do escoamento superficial, os poluentes chegam até os corpos hídricos e se bioconcentram. As gotas de chuva, ao incidirem no solo ou nos telhados, causam pequenas erosões, que desagregam sedimentos e, juntamente com o escoamento superficial, ocorre o arraste e a diluição desses sedimentos, que contêm diversos metais e minerais, os quais são carreados para os rios urbanos.

O objetivo do projeto foi pesquisar as fontes de poluição difusa em ambientes urbanos por compostos inorgânicos, avaliando a contribuição dos componentes de amianto presentes nas telhas de fibrocimento e nos freios de veículos, com aplicação na Bacia do Rio Belém, em Curitiba-PR.

\section{Revisão bibliográfica}

O amianto ou asbesto, como é conhecido, corresponde ao conjunto de fibras minerais constituídas basicamente de silicato de magnésio hidratado, estando presente em 95\% da crosta terrestre. Por meio de pressões e temperaturas que ocorrem nas transformações geológicas, formamse as fibras nas pedras, que são conhecidos como os “cabelinhos” (ASSOCIAÇÃO..., 2010). O
Brasil está entre os cincos maiores produtores, consumidores e exportadores mundiais do amianto crisotila. Sua jazida localiza-se na cidade de Minaçu, em Goiás, explorada por multinacionais, cujos países de origem já foram proibidos de usar amianto. Os Estados de São Paulo, Rio de Janeiro, Pernambuco e Rio Grande do Sul possuem leis estaduais que proíbem o uso do mineral. Outros estados ainda buscam sua proibição. (ASSOCIAÇÃO..., 2010; INSTITUTO..., 2010). Com o desgaste do mineral, liberam-se fibras que podem ser levada pelo ar e que podem desenvolver graves doenças pulmonares quando inaladas (PRODANOFF, 2005).

Segundo o Instituto Nacional de Câncer (INCA), o amianto foi classificado pela Agencia Internacional de Pesquisa (IARC) no grupo 1, que corresponde aos produtos reconhecidamente cancerígenos para os seres humanos e para a exposição às fibras de amianto. $\mathrm{O}$ amianto foi banido em mais de 50 países. Em 1986 a Organização Internacional do Trabalho (OIT) editou a "Convenção de 162", que regulamenta o uso do amianto nas áreas de mineração, nas indústrias de processamento e transformação do minério. Embora países em desenvolvimento ainda liberem o uso do amianto, atribuem limites de tolerância para isso. O amianto crisotila é considerado uma fibra cancerígena pelo critério de Saúde Ambiental 203 do Programa de Segurança Química da Organização Mundial de Saúde (OMS) de 1998. A OMS conclui que nenhum limite de tolerância foi identificado para os agentes carcinogênicos, que, se existirem materiais que substituam o amianto crisotila, estes devem ser considerados para uso, pois a exposição ao mineral aumenta os riscos de asbestose, câncer de pulmão e mesotelioma, em função da concentração (INSTITUTO..., 2010).

No Brasil, o Ministério do Trabalho (MT) publicou em 1991 a Portaria $n^{0} 1$, que foi promulgada somente em 1995 pela Lei no 9.055 (BRASIL, 1995), que regulamenta o controle sobre a extração, industrialização, utilização, comercialização e transporte do amianto e seus derivados, bem como das fibras naturais e artificiais, de qualquer origem, utilizadas para o mesmo fim e dá outras providências (BRASIL, 1995). Com isso, proíbe o amianto anfibólio e qualquer produto que o tenha, sendo liberado somente o uso controlado do amianto crisotila, conhecido também como amianto branco. A Norma Regulamentadora NR 15 (BRASIL, 1995) apresenta os limites de tolerância para poeiras minerais e determina que a exposição dos 
trabalhadores a uma quantidade de duas fibras respiráveis por metro cúbico $\left(\mathrm{m}^{3}\right)$ não causa doenças. As empresas que trabalham com esse material devem possuir um cadastro no Ministério do Trabalho. As principais doenças são asbestose, câncer de pulmão, mesotelioma de pleura e peritônio, doenças pleurais e cânceres de laringe, do aparelho digestivo e de ovário (GIANNASI, 2006; INSTITUTO..., 2010).

As telhas são constituídas de diversos tipos de materiais, entre os quais estão a cerâmica, o fibrocimento, o concreto e metálico. Um telhado caracteriza-se como um revestimento descontínuo constituído por diversos tipos de materiais com o intuito de proteger contra o excesso de luz (raio solares) e contra a água da chuva. A telha de fibrocimento tem durabilidade comprovada. Segundo o IPT (2006), o hangar da base aérea de Santa Cruz (RJ) que abrigava o Zepelim é recoberto com as mesmas telhas Eternit de fibrocimento colocadas na década de 40, que se encontram em bom estado de conservação. Dias (2008) relatou que o cimento-amianto sofre intempéries, porém não há comprometimento das características mecânicas. Ele afirma que o cimento-amianto com 37 anos apresenta desempenho mecânico semelhante ao disponível hoje no mercado brasileiro (LESSA, 2009).

Segundo a Eternit (2010), as telhas de fibrocimento possuem diversos formatos, mas com a mesma composição. O fibrocimento são fibras de amianto e água que obtêm resistência a gases secos e a vapores úmidos (com $\mathrm{pH}$ superior a 6). A composição das telhas da Brasilit (2010) possui em sua composição cimento reforçado com fio sintético, sem a presença de amianto. Na construção civil, são usados em grande escala as telhas de fibrocimento, principalmente nas construções de baixo custo, em cuja composição é usado o amianto (asbesto). Existem fabricantes que substituem a telha de fibrocimento por outros materiais que impactam menos o ambiente e, dessa forma, contribuem para o desenvolvimento sustentável, como (LESSA, 2009):

(a) telha de fibra de celulose, feita com resíduo de papel; (b) telha tetrapak, com resíduos de embalagens de leite longa vida; $\mathrm{e}$

(c) telha-tubo, gerada pelos resíduos de embalagens de creme dental.

Nos veículos o maior desgaste ocorre nos discos, pastilhas e lonas. A composição química dos materiais utilizados na pastilha e lona varia de acordo com o ano, modelo e marca do automóvel, porém o princípio de todos é ferro fundido. Segundo Gay Neto (2004) e informações nas embalagens de pastilhas da Cobreq, os freios são compostos de fibras orgânicas, resinas sintéticas, óxidos metálicos (Cr, Mo, Ni, Cu, Al, Fe e Mg) e cargas minerais. Os freios mais antigos podem ter amianto em sua composição.

\section{Metodologia}

Realizou-se a avaliação da contribuição da poluição difusa gerada pelos componentes presentes nas coberturas das edificações e nos freios de veículos na Bacia Hidrográfica do Rio Belém, localizada na Região Sul do Brasil, no município de Curitiba, estado do Paraná (Figura 1). Segundo os dados do Instituto de Pesquisa e Planejamento Urbano de Curitiba (IPPUC), essa bacia possui área e extensão de aproximadamente $87,85 \mathrm{~km}^{2}$ e $21 \mathrm{~km}$ respectivamente, o que corresponde a $20 \%$ da área do município, englobando 37 bairros. Sua nascente está situada no bairro Cachoeiras, e sua Foz, no Bairro Boqueirão, sendo tributário da margem direita do Rio Iguaçu. Na Bacia estão presentes ocupações residenciais e comerciais, passando por diversos pontos turísticos, e a maior parte da bacia encontra-se canalizada para dar espaço às construções.

\section{Pontos de Análise}

Foram determinados na área da Bacia oito pontos amostrais, sendo quatro pontos (áreas) para realizar a contagem dos veículos e quatro pontos para a contagem das áreas com coberturas (Figura 2). Os círculos brancos são os pontos onde ocorreram as contagens dos veículos, e os quadrados em rosa são os pontos (áreas) de análise dos telhados. 


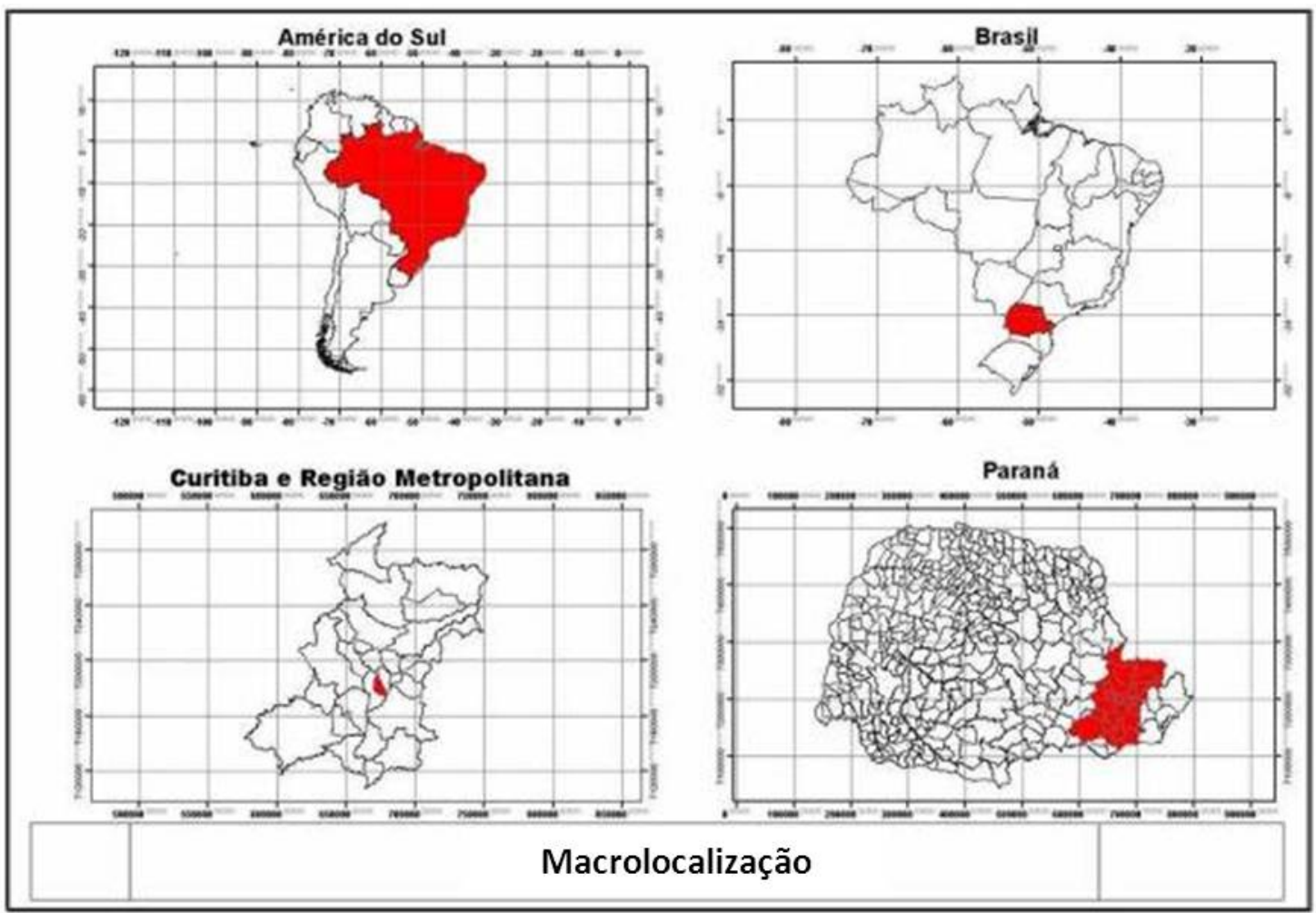

Figura 1 - Macrolocalização da bacia do Rio Belém
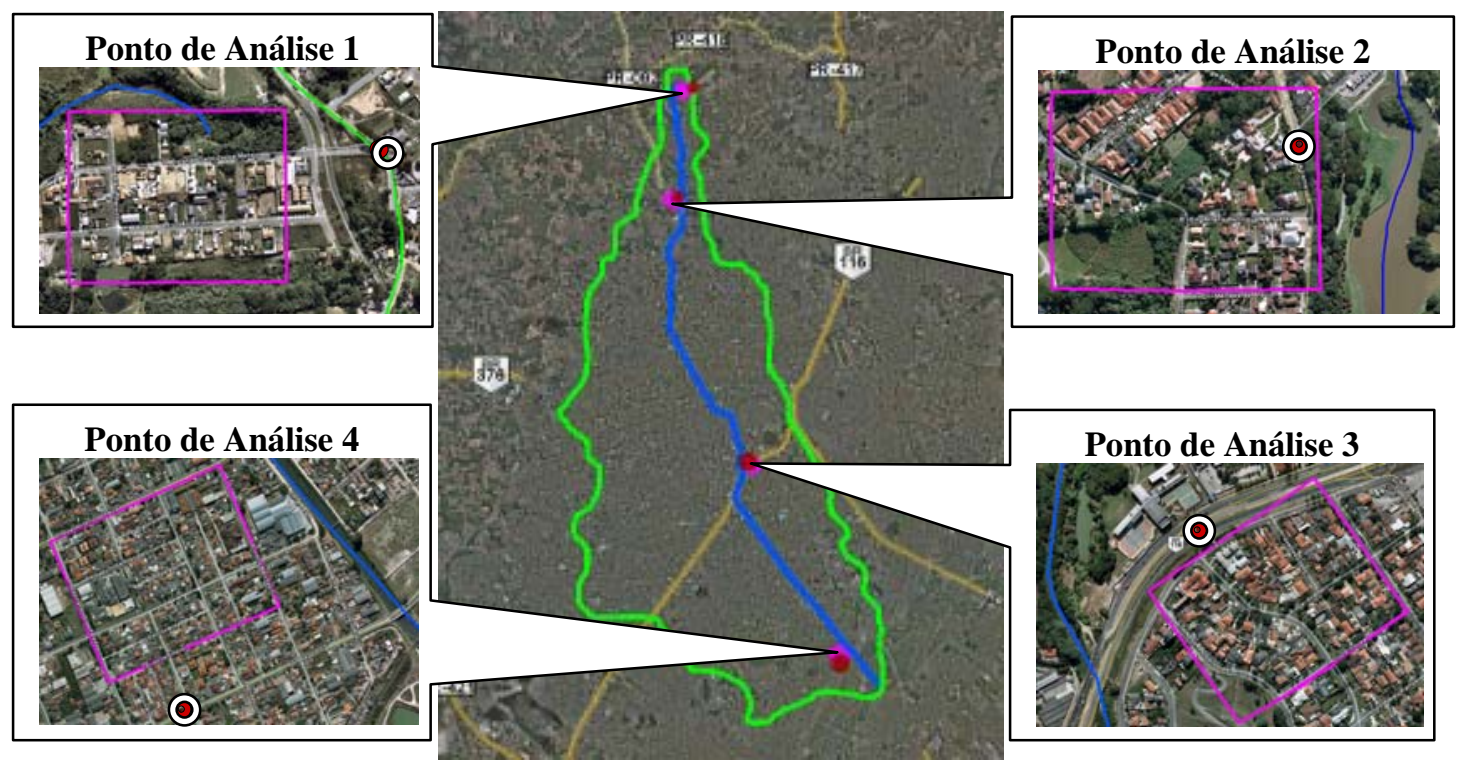

Figura 2 - Localização dos pontos de análises na Bacia do Rio Belém

Através do software AutoCAD ${ }^{\circledR}$ (2002), foram realizadas as medições dos telhados nas áreas dos quatro pontos, diferenciando três tipos de telhados por cores: telhados de cor cinza foram considerados com amianto; de cor marrom, sem amianto; e de demais cores, como não identificados. Nem todos os telhados de cor cinza são de fibrocimento amianto, assim como não é possível afirmar que todos os telhados marrons são telhas de barro. Hoje, muitas coberturas são tingidas das cores que cada morador quer, portanto os dados dão estimativas e indicadores da presença ou não do tipo do material (Tabela 1).

\section{Análise do fluxo de veículos}

Nos quatro pontos de análise, realizou-se a contagem do número de veículos por hora, 
analisados dentro do período das 13h30min às 17h30min durante os dias de segunda a sexta-feira. Com isso aplicou-se a quantidade de $\mathrm{Mg}$ que é liberada juntamente com os outros materiais no desgaste natural das pastilhas no ato de parar o veículo.

Tabela 1 - Plano de análise dos telhados

\begin{tabular}{|c|c|c|c|}
\hline Telhados & Áreas $\left(\mathrm{m}^{2}\right)$ & Porcentagem (\%) & Ponto 1 - Áreas de amostragem \\
\hline Com amianto (cinza) & $2.764,36$ & 35,48 & \\
\hline Sem amianto (marrom) & $1.880,35$ & 24,14 & \\
\hline Não identificado & $3.146,88$ & 40,38 & \\
\hline \multicolumn{4}{|c|}{$\begin{array}{l}\text { Área total (m²): 78.111,5 } \\
\text { Latitude: 2521’14.04” S } \\
\text { Longitude: 49¹5’58.55” O }\end{array}$} \\
\hline Telhados & Áreas $\left(m^{2}\right)$ & Porcentagem (\%) & Ponto 2 - Áreas de amostragem \\
\hline Com amianto (cinza) & $5.512,67$ & $32,67 \%$ & \multirow{4}{*}{ Ponto 3 - Áreas de amostragem } \\
\hline Sem amianto (marrom) & $10.078,34$ & $59,74 \%$ & \\
\hline Não identificado & $1.278,88$ & $7,59 \%$ & \\
\hline \multicolumn{4}{|c|}{$\begin{array}{l}\text { Área total }\left(\mathrm{m}^{2}\right): 103.887,69 \\
\text { Latitude: } 25^{\circ} 23^{\prime} 00.23 ” \mathrm{~S} \\
\text { Longitude: } 49^{\circ} 16^{\prime} 10.23^{\prime} \mathrm{O}\end{array}$} \\
\hline Telhados & Áreas $\left(\mathrm{m}^{2}\right)$ & Porcentagem (\%) & \\
\hline Com amianto (cinza) & $3.950,39$ & 18,53 & \\
\hline Sem amianto (marrom) & $15.405,89$ & 72,28 & \\
\hline Não identificado & $1.958,01$ & 9,19 & \\
\hline \multicolumn{4}{|c|}{$\begin{array}{l}\text { Área total }\left(\mathrm{m}^{2}\right): 81.783,71 \\
\text { Latitude: } 25^{\circ} 27^{\prime} 20.08 ” \mathrm{~S} \\
\text { Longitude: } 49^{\circ} 14^{\prime} 45.399^{\prime} \mathrm{O}\end{array}$} \\
\hline Telhados & Áreas $\left(\mathrm{m}^{2}\right)$ & Porcentagem (\%) & Ponto 4 - Áreas de amostragem \\
\hline Com amianto (cinza) & $25.472,93$ & 60,30 & \multirow{4}{*}{ 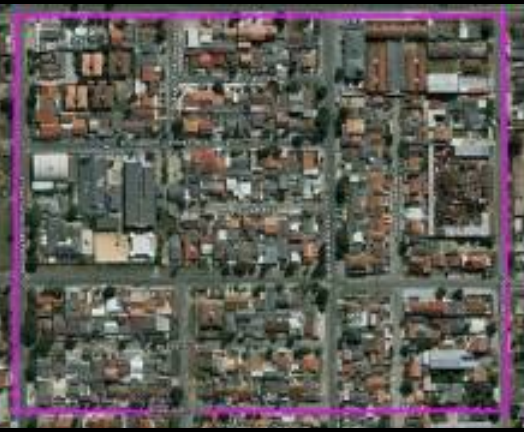 } \\
\hline Sem amianto (marrom) & $11.479,61$ & 27,17 & \\
\hline Não identificado & $5.290,74$ & 12,53 & \\
\hline \multicolumn{3}{|c|}{$\begin{array}{l}\text { Área total (m²): 121.900,92 } \\
\text { Latitude: } 25^{\circ} 30 ’ 24.30^{\prime} \mathrm{S} \\
\text { Longitude: } 49^{\circ} 13^{\prime} 11.66^{\prime} \mathrm{O}\end{array}$} & \\
\hline
\end{tabular}

Fonte: Google Earth (2009). 


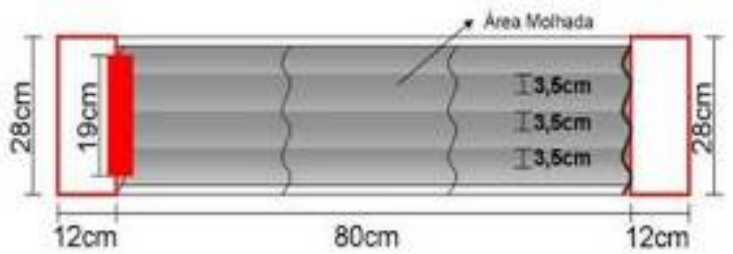

(a) Representação da superfície da telha e dimensionamento

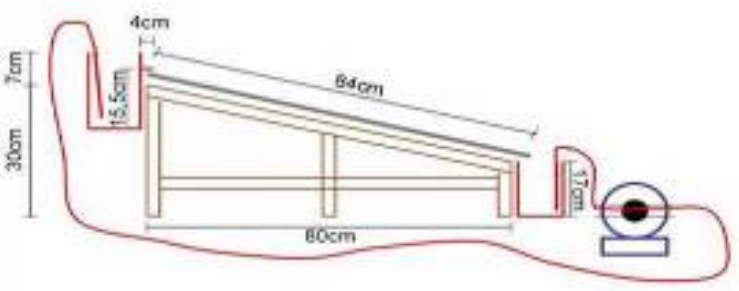

(c) Representação lateral e dimensionamentos

Figura 3 - Projeto piloto

\section{Análise do desgaste das telhas}

Para analisar o possível desgaste das telhas foi elaborado um projeto piloto, o qual possui um suporte de madeira para as telhas, dois reservatórios de água, duas bombas com vazão total $0,028 \mathrm{l} / \mathrm{s}$ e duas mangueiras que ligam igualmente um reservatório ao outro. O projeto piloto e as dimensões utilizadas podem ser visualizados na Figura 3a, 3b, 3c e 3d. A telha utilizada, fabricada pela Imbralit $^{\circledR}$, possuía um diâmetro de $4 \mathrm{~mm}$.

Para a simulação da água de chuva em um telhado, utilizou-se uma solução de chuva sintética preparada de acordo com os procedimentos sugeridos por (DAVIS et al. 2001 ${ }^{1}$ apud PUSCH, 2007), cujos reagentes são $\mathrm{H}_{2} \mathrm{SO} 4$, $\mathrm{HNO} 3$ e $\mathrm{NaCl}$, nas proporções que podem ser visualizadas na Equação 1. O pH da solução era de 4,0 e foi alterado para 5,5, que é o pH médio das precipitações de Curitiba (SIMEPAR, 2005² apud PUSCH, 2007). Para a alteração do $\mathrm{pH}$ foi utilizado hidróxido de sódio.

$23 \mu \mathrm{mol} \mathrm{L} \mathrm{L}^{-1}(\mathrm{NaCl})+18 \mu \mathrm{mol} \mathrm{L}-1\left(\mathrm{H}_{2} \mathrm{SO}_{4}\right)+18$ $\mu \mathrm{mol} \mathrm{L}{ }^{-1}\left(\mathrm{HNO}_{3}\right)$

\section{Análises laboratoriais}

Para as análises laboratoriais realizaram-se os métodos sugeridos pelo Standard Methods (1998a). As amostras de telha de fibrocimento amianto e de uma pastilha de freio com amianto foram digeridas em ácido nítrico, seguindo o

\footnotetext{
${ }^{1}$ DAVIS, A.P.; SHOKOUHIAN, M.; NI, S. Loading Estimates of Lead, Copper, Cadmium and Zinc in Urban Runoff from Specific Sources. Chemosphere, v. 44, n. 5, p. 997-1009, 2001.

2 SIMEPAR. [Sobre]. Disponível em :

\ttp:// www.simepar.com. br>. Acesso em: 09 abr. 2009.
}

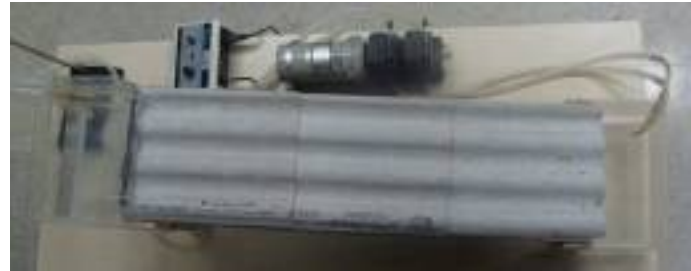

(b) Imagem real da superfície

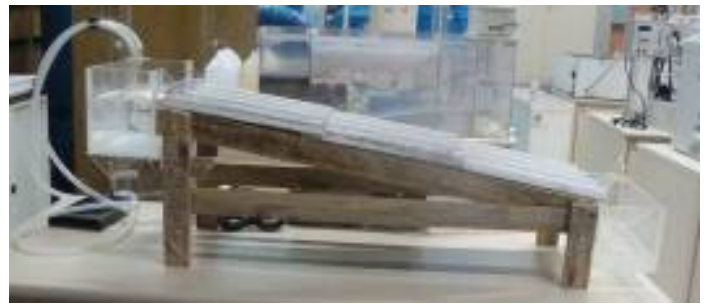

(d) Imagem real lateral

método 3030E. Depois se realizou a leitura do silício (Si) e do magnésio (Mg), que são os componentes presentes no amianto crisotila, no aparelho de Espectrofotoscopia de Absorção Atômica (EAA), modelo 250 Plus, da marca Varian, seguindo o método 3111D (STANDARD..., 1998b).

Para o cálculo da amostra de base úmida usou-se a Equação 1.

Amostra base úmida $=\frac{\text { Valor do EAA (mg/l) } \times \text { Volume da Digestăo }}{\text { Quantidade de gramas usada na amostra }}$

Eq. (1)

\section{Estimativa das áreas de telhado na Bacia}

A análise e a caracterização foram realizadas com o software Google Earth 6 (2009) e o AutoCAD ${ }^{\circledR}$ (2002), pelos quais se diferenciaram os tipos de telhados, classificadas em três tipos: telhas de fibrocimento amianto (com amianto, representadas pela cor cinza); telhas de barro ou cerâmica (sem amianto, representadas pela cor marrom); e as que não foram passíveis de identificação a partir das cores.

\section{Resultados e discussão}

O diagnóstico do efeito poluidor do desgaste dos freios de veículos e das telhas de fibrocimento amianto na Bacia do Rio Belém foi analisado com base em levantamentos bibliográficos e em análise de quatro pontos amostrais na Bacia. Em cada ponto verificou-se o fluxo de veículos e a possível quantificação de áreas com telhados. Devido a dificuldades encontradas tanto na locomoção para realizar visitas em campo quanto em análises mais específicas dos materiais presentes nos freios e nas telhas, não se pode afirmar que o levantamento foi 
completo na área de estudo, recomendando-se análises mais profundas.

Nas análises realizadas quanto à quantidade de Si e Mg presentes em uma telha de fibrocimento amianto, em uma pastilha de freio da marca Cobrec e no desgaste da telha de fibrocimento amianto do projeto piloto (Tabela 2), apenas na pastilha de freio não foram detectados traços de Si.

Desde 2004, não são fabricadas mais pastilhas de freio com amianto, porém elas ainda podem ser encontradas em veículos mais antigos. Hoje, os metais pesados são os mais prejudiciais da poluição difusa causada pelas pastilhas. Na Tabela 3 , observa-se o número de carros quantificados e os valores estimados do desgaste das pastilhas em cada ponto, lembrando que os valores estão sendo considerados somente os de uma roda de cada veículo.

O ponto que teve maior número de veículos por hora é uma das rodovias mais movimentadas de Curitiba, por isso o elevado número de veículos por hora e uma maior concentração de desgaste do material.

As quantidades de Si e Mg desprendidas da telha do projeto piloto, nas áreas analisadas na Bacia, podem ser observadas na Tabela 4. Essas análises foram realizadas em uma telha nova, que foi lavada antes de se realizar o procedimento, para que não tivesse nenhuma interferência de partículas desprendidas (pó). A simulação da chuva foi realizada somente por 18 horas.

A quantidade de material liberado é consideravelmente alta. Essas partículas acabam sendo carreadas e atingem os corpos hídricos. Porém, segundo o IPT (2006), a maior degradação ocorre na camada mais superficial da telha, e o processo de lixiviação é o que menos desgasta a telha. É a umidade o fator que leva ao aumento da porosidade das telhas, ocasionando a degradação dos compósitos do cimento-amianto. Essas análises também revelaram que as telhas que estão expostas às intempéries degradam menos que as que estão guardadas em galpões.

Tabela 2 - Concentração das análises por espectrometria de absorção atômica

\begin{tabular}{cccc}
\hline Parâmetro & Área aplicada & Si & Mg \\
\hline Telha de fibrocimento amianto & $100 \mathrm{~g}$ & $0,087 \mathrm{~g}$ & $1,16 \mathrm{~g}$ \\
Pastilha de freio com amianto & $100 \mathrm{~g}$ & Não detectado & $5,87 \mathrm{~g}$ \\
Concentração do material lixiviado no projeto piloto & $0,84 \mathrm{~m}^{2}$ & $0,0102 \mathrm{~g} / \mathrm{l}$ & $0,3702 \mathrm{~g} / \mathrm{l}$ \\
\hline
\end{tabular}

Tabela 3 - Análise estimada do desgaste de uma roda de veículo aplicado na quantidade de carros que passam em uma hora em cada ponto

\begin{tabular}{|c|c|c|c|c|c|c|c|c|}
\hline \multirow{3}{*}{ Pontos } & \multirow{3}{*}{ Localização } & \multirow{3}{*}{$\begin{array}{l}\text { Número } \\
\text { de carros }\end{array}$} & \multicolumn{6}{|c|}{ Desgaste das pastilhas de uma roda (gramas) } \\
\hline & & & \multicolumn{2}{|c|}{ Ano } & \multicolumn{2}{|c|}{ Dia } & \multicolumn{2}{|c|}{ Hora } \\
\hline & & & Total & $\begin{array}{c}\mathrm{Mg} \\
(5,87 \%)\end{array}$ & Total & $\begin{array}{c}\text { Mg } \\
(5,87 \%)\end{array}$ & Total & $\begin{array}{c}\mathrm{Mg} \\
(5,87 \%)\end{array}$ \\
\hline 1 & Rua Anita Garibaldi & 960 & $1.204,400$ & 70,690 & 3,360 & 0,197 & 0,140 & 0,00808 \\
\hline 2 & Rua Matheus Leme & 506 & 633,760 & 37,201 & 1,711 & 0,100 & 0,073 & 0,004 \\
\hline 3 & Rod. Regis Bittencourt & 3.376 & $4.235,470$ & 248,622 & 11,816 & 0,693 & 0,492 & 0,028 \\
\hline 4 & Rua Dr. Bley Zornig & 887 & $1.112,810$ & 65,321 & 3,104 & 0,182 & 0,129 & 0,007 \\
\hline
\end{tabular}

Tabela 4 - Análise do desprendimento das partículas de Si e Mg de um telha de fibrocimento amianto com aplicação nas áreas com coberturas de telhas de fibrocimento amianto nos pontos da Bacia do Rio Belém

\begin{tabular}{c|c|c|c}
\hline \multirow{2}{*}{ Pontos } & \multirow{2}{*}{ Área de telhados cinzas $\left(\mathbf{m}^{\mathbf{2}}\right)$} & \multicolumn{2}{|c}{$\begin{array}{c}\text { Componentes lixiviados com a } \\
\text { solução chuva sintética (g/l) }\end{array}$} \\
\cline { 3 - 4 } & & \multicolumn{2}{|c}{$\mathbf{1 8 ~ h}$ de chuva } \\
\cline { 3 - 4 } & & $\mathbf{S i}$ & $\mathbf{M g}$ \\
\hline 1 & $2.764,36$ & 33,57 & $1.218,29$ \\
2 & $5.512,67$ & 66,93 & $2.428,19$ \\
3 & $3.950,39$ & 47,97 & $1.740,99$ \\
4 & $25.472,93$ & 309,31 & $11.226,28$ \\
Total & $\mathbf{3 7 . 7 0 0 , 3 5}$ & $\mathbf{4 5 7 . 7 8}$ & $\mathbf{1 6 . 6 0 3 . 7 5}$ \\
\hline
\end{tabular}


Das áreas analisadas, o ponto 1, além de ser a área menos ocupada, está próximo ao parque da nascente, ponto onde teve mais telhados não identificados, isso por possuir muitas ocupações irregulares. Os pontos 2 e 3 são os mais próximos ao centro urbano e ambos tiveram mais de $50 \%$ dos telhados da cor marrom, possivelmente telhas de barro ou cerâmica, por ser uma região onde as pessoas tendem a ter uma condição financeira melhor. O ponto 4 teve a maior área com telhados cinzas, o que ocorre por ser a área com mais ocupações por espaço em relação aos outros pontos e devido ao fato de as pessoas possuírem uma condição financeira mais baixa. A Bacia está inteiramente dentro do município de Curitiba, e a intensa busca por espaço acaba levando à ocupação de cada vez mais áreas próximo à Bacia.

Quanto à presença do amianto, constatou-se que o único dano à saúde comprovado por pesquisas científicas ocorre pela inalação da fibra de amianto. Já os danos à saúde não foram comprovados cientificamente quando o contato do mineral é cutâneo ou quando ele é ingerido com água ou algum alimento, porém o Ministério da Saúde orienta que seja evitado contato com o mineral em todas as formas até que haja pesquisas mais aprofundadas.

Com relação às análises dos componentes das telhas, observou-se que ocorreu uma degradação considerável. De acordo com pesquisas anteriores, isso se deve ao fato de a telha ser nova e as análises no projeto piloto realizadas em uma área com umidade considerável, portanto, propiciando a degradação da superfície da telha. Quanto aos freios, analisou-se o possível desgaste dos veículos e pode-se afirmar que, quanto maior o fluxo de veículos, maior será a concentração de poluentes liberados. Tanto nas telhas quanto nos freios, não foi possível realizar as análises nas águas da Bacia devido à dificuldade de se encontrar um aparelho que, além de caracterizar e quantificar as partículas provenientes deles, pudesse informar que os componentes encontrados nas águas são realmente das telhas e dos freios, pois existe amianto em muitos outros materiais.

\section{Conclusão}

Com os estudos realizados constatou-se que ocorre a poluição difusa. As fontes analisadas advêm de um desgaste nos freios, que é um processo mecânico de fricção no ato de parar um veículo, e de um processo de intemperismo nas telhas de fibrocimento. Com isso, sugere-se a interrupção da fabricação de telhas com componentes de amianto, o que diminuirá a presença dele no meio urbano. Hoje, o Brasil já possui diversos substitutos para o amianto, portanto não haverá grande impacto econômico para o país com essa ação.

\section{Referências}

ANDREOLI, C. V. et al. A Crise da Água e os Mananciais de Abastecimento. In: ANDREOLI, C. V. Mananciais de Abastecimento: planejamento e gestão. Curitiba: Sanepar; Finep, 2003.

ASSOCIAÇÃO BRASILEIRA DOS EXPOSTOS AO AMIANTO. Amianto ou Asbesto: o inimigo mortal que ronda nossas vidas. Disponível em:<http://www.abrea.com.br/inde_inimigo.pdf $>$. Acesso em: 24 jul. 2010.

AUTOCAD $^{\circledR}$. [Software]. 2002. Disponível em: $<$ http://usa.autodesk.com/adsk/servlet/ps/dl/index? siteID=123112\&id=2334435\&linkID=9240618\#se ction10>. Acesso em: 10 ago. 2009.

\section{BILBAO, D. Termo de Referência para a}

Confecção do Manual de Prevenção da Poluição Difusa em Meio Antrópico. 2007. Trabalho de Conclusão de Curso (Graduação) - Faculdade de Engenharia Ambiental,a Pontifícia Universidade Católica do Paraná, Curitiba, 2007.

BRASIL. Lei No 9.055, de 1 de Julho de 1995, disciplina a extração, industrialização, utilização, comercialização e transporte do asbesto/amianto e dos produtos que o contenham, bem como das fibras naturais e artificiais, de qualquer origem, utilizadas para o mesmo fim. Disponível em: $<$ http://www.planalto.gov.br/ccivil_03/leis/L9055. htm>. Acesso em 28 set. 2010.

BRASIL. NR No 15: limites de tolerância para poeiras minerais. 1995. Disponível em:

<http://www.crisotilabrasil.org.br/site/leisNormas/ _pdf/normaRegulamentadoraNR15ComAnexo.pdf >. Acesso em: 28 set. 2010.

BRASILIT. Disponível em:

<http://www.brasilit.com.br/produtos/index_produ tos.php>. Acesso em: 20 jan. 2010.

DIAS, C. M. R. et al. Envelhecimento de Longo Prazo de Telhas Onduladas de Fibrocimento: o efeito da carbonatação, lixiviação e chuva ácida. Cement \& Concrete Composites, v.30, n. 6, p. 255-265, abr. 2008.

ETERNIT. Disponível em:

<http://www.eternit.com.br/produtos/telhasdefibro cimento/index.php?>. Acesso em: $22 \mathrm{dez} .2010$.

GAY NETO, A. et al. Seleção de Materiais Para Sistema de Freio a Disco Automotivo. São Paulo: [s.n.], 2004.

GIANNASI, F. Amianto ou asbesto.

Minaçu/Goiás: [s.n.], 2006. 
GOOGLE EARTH 6.0. [Imagem]. Disponível em: <http://www.google.com/earth/index.html>. Acesso em: 22 maio 2009.

INSTITUTO NACIONAL DE CÂNCER.

Amianto. Disponível em:

$<$ http://www.inca.gov.br/conteudo_view.asp?ID=1

5>. Acesso em: 12 abr. 2010.

INSTITUTO DE PESQUISAS

TECNOLÓGICAS. Estudo das Alterações das

Telhas de Cimento-Amianto ao Longo do Uso,

Pela Exposição às Intempéries. Butantã: IPT,

2006. Relatório técnico n ${ }^{\circ} 85$ 176-205.

LESSA, M. L. S. Critérios de Sustentabilidade

Para Elementos Construtivos: um estudo sobre telhas “ecológicas” empregadas na construção civil. 2009. 153 f. Dissertação (Mestrado em Engenharia Ambiental Urbana) - Escola de Politécnica, Universidade Federal da Bahia, Salvador, 2009.

PUSCH, P. B. Inventário de Cargas de Metais a Partir de Fontes Difusas de Poluição.

Dissertação (Mestrado em Engenharia Civil) Faculdade de Engenharia Civil, Arquitetura e Urbanismo, Universidade Estadual de Campinas, Campinas, SP, 2007.
PRODANOFF, J. H. A. Aplicação de Poluição Difusa Gerada por Enxurradas em Meio Urbano. Rio de Janeiro. 2005. Tese (Doutorado em Ciências em Engenharia Civil) - Escola de Engenharia, Universidade Federal do Rio de janeiro, Rio de Janeiro, 2005.

STANDARD METHODS for the Examination of Water and Wastewater. 3030E: método de digestão das amostras em ácido nítrico. 20. ed. $1998 a$.

STANDARD METHODS FOR THE

EXAMINATION OF WATER AND

WASTEWATER. 3111D: método de Metals by Flame Atomic Absorption Spectrometry. 20. ed. 1998b.

TOMAZ, P. Poluição Difusa. São Paulo: Navegar, 2006.

Revista Ambiente Construído

Associação Nacional de Tecnologia do Ambiente Construído

Av. Osvaldo Aranha, 99 - 30 andar, Centro

Porto Alegre - RS - Brasil

CEP $90035-190$

Telefone: +55 (51) 3308-4084

Fax: +55 (51) 3308-4054

www. seer. ufrgs. br/ ambienteconstruido

E-mail: ambienteconstruido@ufrgs.br 